\title{
RESULTS AND CONCLUSIONS OF THE PROJECT “COMPLEX MODEL FOR RISK ASSESSMENT AND TREATMENT IN INDUSTRIAL PROCESSES" (MOPORI)
}

This article deals with selected results and conclusions which were achieved in the project APVV 0043-10 MOPORI during more than three years of its solution. The area of major industrial accidents prevention is very specific and concerns all EU member states. At the beginning we will describe the current state and bases of the project together with identification of the problem areas. In the next part we will aim at describing the algorithm created for assessing and managing the risks. Here we implemented suitable qualitative and quantitative methods and we will explain its applicability. Subsequently we will present software means for creating scenarios and assess the currently realised application of the model. This application is an inevitable part for verifying the procedures and schemes created.

Keywords: Industrial Accidents Prevention, SEVESO, Complex Model, MOPORI.

\section{Introduction}

The Slovak Republic with its area is relatively a small country compared with other European states. However, its small territory does not guarantee that major industrial accidents do not concern our country. The industrial production has a significant share of the Slovak economy and on $22^{\text {nd }}$ August 201483 companies belonged to the SEVESO directive. Out of this, 38 companies is in the lower A category and 45 belong to the higher B category [1].

In the $\mathrm{EU}$ the area of the major industrial accidents prevention is adapted according to the SEVESO directive. The adaptations of the directive have followed the long-term development since its introduction in 1982 until now. Thanks to more and more sophisticated system of communication, information flows about accidents and also feedbacks from the industrial enterprises and citizens it has been possible to adapt the directive in the form we know today. Slovakia adopted the directive SEVESO II and implemented it to its legislation in 2002 when the law No 261/2002 Coll., about major industrial accidents prevention and implementing regulations were adopted. In this way the directive SEVESO II was implemented into the system. Currently in Slovakia there are working meetings which prepare a new law about accidents and this new law will transpose the directive SEVESO III to our national legislation - this new law will become effective on $1^{\text {st }}$ June 2015 . The new rules will strengthen the legal regulations in the area of major industrial accidents prevention and ensure the necessary high level of protecting lives and health of people as well as our environment [2].

The current time period creates space for implementing new approaches in the area of processing the safety and security documentation. One of the problem areas is also assessment and management of risks and this fact has been documented in several regulations and documents [3 and 4]. Based on the changes in process and problems in the area of assessing and treating risks the team at the Faculty of Security Engineering at the University of Zilina decided to submit a project under the name "Complex Model for Risk Assessment and Treatment in Industrial Processes" which is kept on file under the number APVV 0043-10 and abbreviation MOPORI.

\section{Results and Outputs of the Project MOPORI}

The first step after accepting the project was to carry out a deeper and more comprehensive analysis of the then current state in the area of major industrial accidents prevention for to specify or to change the partial project goals. The main aim was to create a model which would respect the requirements of

\footnotetext{
* ${ }^{1}$ Katarina Holla, ${ }^{2}$ Maria Simonova, ${ }^{3}$ Jan Kandrac, ${ }^{4}$ Stanislav Maly, ${ }^{5}$ Andrew Collins

${ }^{1}$ Department of Crisis Management, University of Zilina, Slovakia

${ }^{2}$ Department of Fire engineering, University of Zilina, Slovakia

${ }^{3}$ Risk consult s.r.o., Bratislava, Slovakia

${ }^{4}$ Occupational Safety Research Institute, Praha, Czech Republic

${ }^{5}$ Department of Geography, Northumbria University, Newcastle, Great Britain

E-mail: Katarina.Holla@fsi.uniza.sk
} 
the European directive SEVESO and the routine procedures in Slovakia in the area of major industrial accidents assessment and treatment.

To fulfil this goal it was necessary to establish cooperation with institutions which deal with this area not only in Slovakia but also in other EU member states. They are Ministry of Environment - Department of Environmental Risks and Biological Security, Bratislava; Slovak Environmental Agency, Banska Bystrica; Risk Consult, s.r.o., Bratislava; Mondi SCP a.s., Ruzomberok; Evonic Fermas, s.r.o., Slovenska Lupca; Vyskumny ustav bezpecnosti prace, Praha; Institut krizoveho manazmentu, Praha; Disaster and Development Centre, Newcastle, UK. Specialists from these institutions created the "Board of Experts" which met regularly and organised workshops for the goals of the project to be fulfilled through brainstorming and other methods.

A further inevitability was to complete the qualification requirements of individual investigation team members who participated in creating the model and its implementation in the companies. They were certificates of the safety and fire safety officers, specialists in the area of major industrial accidents prevention and safety and security advisor ADR.

As we have said already, the first step was to analyse the current state in the area of major industrial accidents prevention. Important information and bases not only for creating the complex model but also for other tasks were summarised in the monograph „Prevencia zavaznych priemyselnych havarii“"Prevention of major industrial accidents) [2].
A chapter under the name "Statistical Research of SEVESO Enterprises" is part of this book. This document was presented in the form of a research report reviewed by the Board of Experts. The document was subsequently revised. Its partial results served as a basic material for preparation of the new law which will become effective in 2015. A statistical questionnaire was sent to 81 companies and 44 pieces were returned. Figure 1 shows the representation of individual lines of business [3].

Based on research results we can ascertain a few facts as follows (these conclusions were stated in the case of questions answered minimally by $50 \%$ of companies/responders):

- the level of collaboration of eligible and authorised safety persons with the company management is very good,

- the methods ETA, FTA and security and safety inspections are used in the framework of utilising the methods and techniques,

- almost unambiguously the companies require sending the safety documentation by electronic mail,

- Excel and Aloha are the software means/environments used by the companies,

- from the point of view of the costs for major industrial accidents prevention the companies spend 0 - 20,000 EUR,

- the majority of the companies involved has a company ranked in the risk area in its neighbourhood and collaboration between them is generally good,

- the companies evaluate the collaboration with state administration bodies as very good, etc. [3].

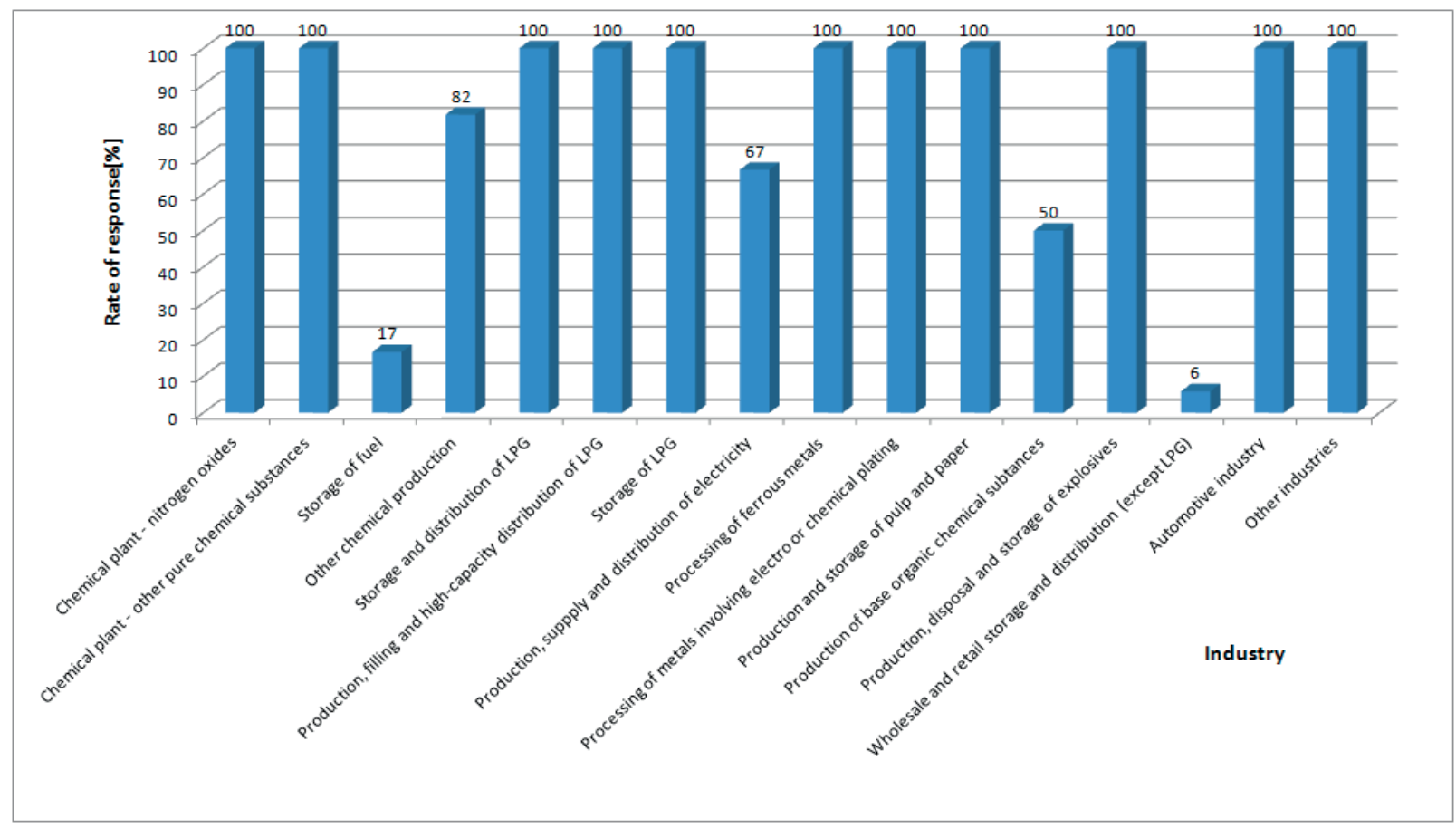

Fig. 1 Rate of return of the questionnaires according to lines of business [\%] [3 and 10] 


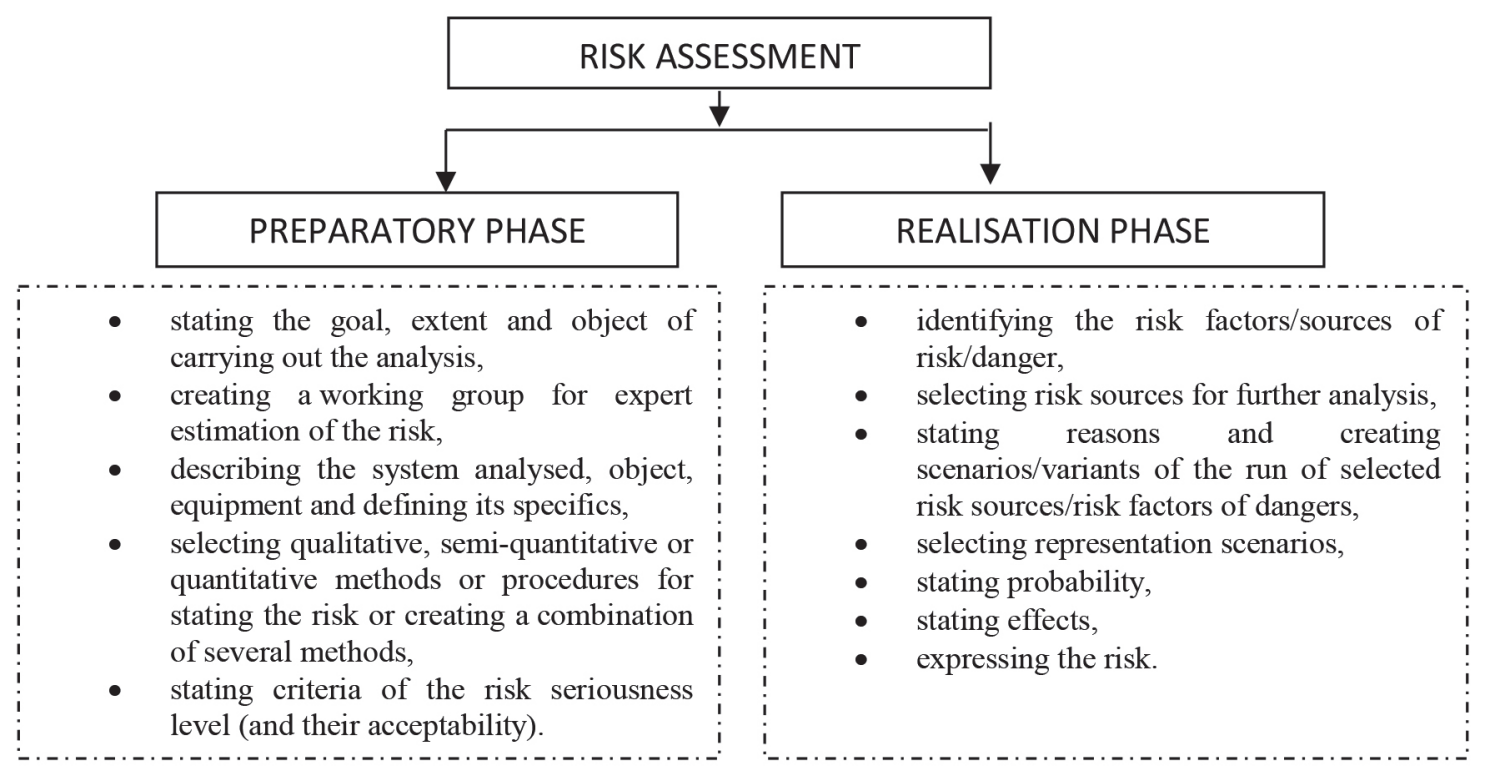

Fig. 2 A simplified model for risk management assessment

All results and conclusions of the current state analysis entered the second phase of the project solution, i.e. creation of the Complex Model for Risk Assessment and Treatment. At the beginning the individual model phases were defined and for each model phase steps of the model were determined. Procedural development diagrams for individual model phases were created. Methods/parts of systematic procedures were implemented into individual steps of the model and subsequently the functional dependences between individual phases and steps of the model were defined. Based on the detected assumptions and the analysis of the currently used reference but also modern approaches/ methods a model for assessing the industrial processes risks which was verified on the basis of a practical application in two SEVESO companies was designed and created. This complex model is based on development diagrams and is too extensive; therefore, we introduce only its simplified version (see Fig. 2).

Methods and techniques which are utilised not only in the systematic procedure ARAMIS but also those which were assessed as suitable for usage in the model on the basis of the research were integrated into individual steps of the complex model [5]. The software programme iMotylik (iButterfly) was created in the framework of this step. It represents a new approach and connection of FTA and ETA which had pre-defined causes and effects in the ARAMIS approach. They were transferred to the

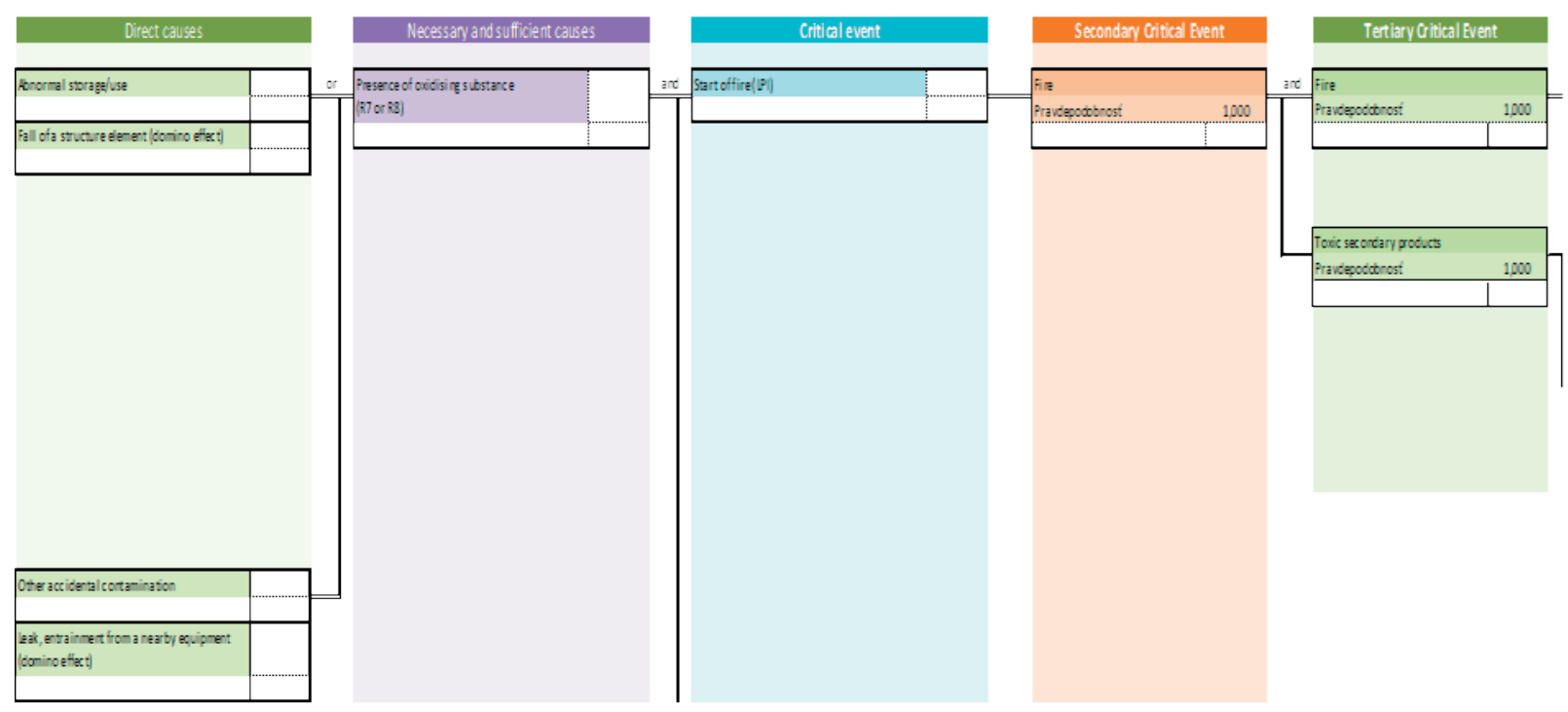

Fig. 3 Cut - out of A bow tie start of fire 
software and the calculation relations based on Boolean algebra and other calculation relations were completed [6]. Innovative approaches to simplify the utilisation of the means by end users were introduced. This software was created on the basis of research activities of the MOPORI project where all generic trees were formed in the Excel environment (the environment chosen on the basis of statistical research 2013 - Holla et al., 2013) according to the causes, effects and impacts pre-defined in the ARAMIS approach and adapted according to currently used approaches in Slovakia. There are 47 of them. One of the simpler trees created in the MOPORI framework - iMotylik (the tree is part of the software iMotylik) is depicted in Fig. 3. It is a bow-tie with a critical event - "start of fire".

In the next step we will determine the development of leakage, explosion and fire of hazardous substances which is simulated by the software ALOHA and based on this it is possible to determine impacts on life, health, property and environment. After using the scenarios (bow-tie diagrams) only those branches which have a potential to develop to a major industrial accident are selected and they are then assessed (unacceptable risks) - Fig. 4. At the end measures for reducing the unacceptable risks are designed. In this risk matrix there are depicted frequencies (y axle) and impact categories (x axle).

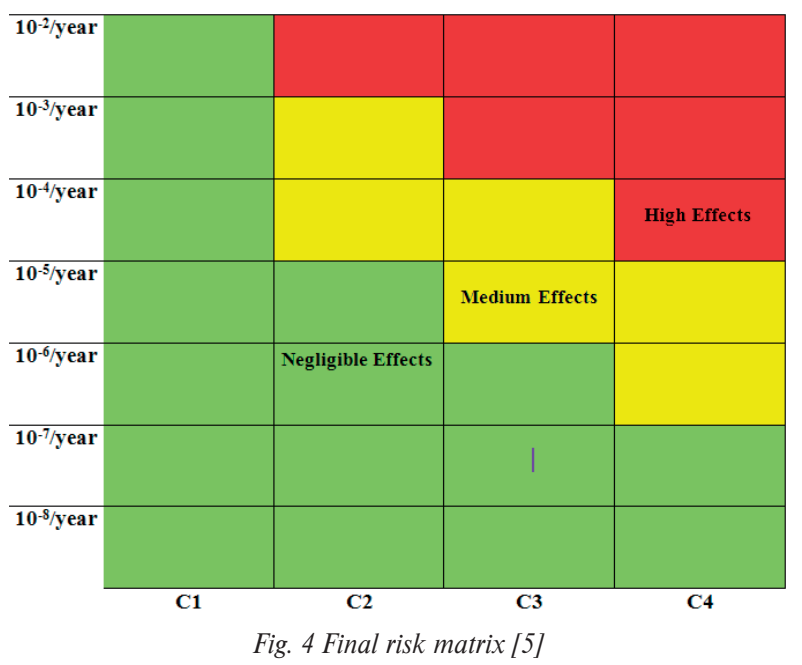

A complex model and its description are much more extensive and complex and a special document which will serve as a methodological aid for its implementation will be issued.

\section{Implementation of the Complex Model and Software in SEVESO Companies}

The model has been implemented in two SEVESO companies in Slovakia - EVONIC Fermas s.r.o (further only
Evonic) and Mondi SCP Ruzomberok a.s. (further only Mondi). Both companies belong under the law about major industrial accidents prevention. The aim was to verify the operation of the complex model and software iMotylik in practice and to compare if the approach designed in the project is simpler and more systematic than that one which was used in the companies before. Two teams were created and each of them dealt with one application. The first results are ready and at the end of September there will be a meeting where the results will be compared and corresponding conclusions taken. Partial results are introduced in the further text. Evonic orients on producing bio-technological products, predominantly amino acids using fermentation processes. From the point of view of the directive SEVESO II/SEVESO III they work only with one hazardous substance in a greater amount $-28-31 \%$ solution of ammonia water. First of all it was necessary to carry out comparison tests in the lab of the Faculty of Security Engineering in Zilina concerning the speed of ammonia evaporation at a certain temperature (see Fig. 5).

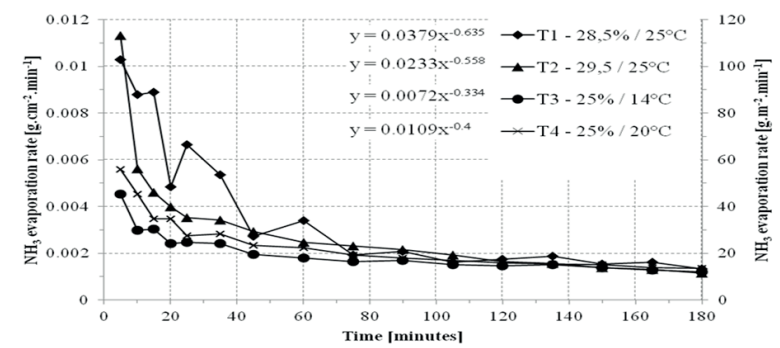

Fig. $5 \mathrm{NH}_{3}$ Evaporation rate as function of time [7]

The diagram confirms a strong dependence of the evaporation rate on the concentration of the ammonia solution as well as ambient temperature. Since T1 and T2 were both conducted with a higher concentration and at a higher ambient temperature, the rate of evaporation is greater (mainly in the first 10-20 minutes). Following the initial period the evaporation rate quickly drops down and the differences between the individual tests are much smaller. The effect of the higher concentration and ambient temperature is still observable. At 5 minutes the highest evaporation rate (T2/113 g. $\left.\mathrm{m}^{-2} \cdot \mathrm{min}^{-1}\right)$ is approximately $150 \%$ higher than the lowest one (T3/45 g. $\left.\mathrm{m}^{-2} \cdot \mathrm{min}^{-1}\right)$. For comparison, at 20 minutes the difference drops to $100 \%$ and at 45 minutes to $50 \%$.This behaviour is most likely attributed to the self-cooling of the sample due to ammonia evaporation [7].

During the further phase we assessed the risk through the complex model and several conclusions were indicated. Although the company (when we assess the social acceptability) still does not belong to the socially acceptable risk, the implementation of the model and selected parts of the methodology of the complex model and taking into account the adopted organisational and technical measures (water screen in the store of the ammonia water) showed interest of the operator to take systematic 
measures to suppress the risk of great leakages of the ammonia water and the gaseous ammonia. At the same time the creation of the barriers (water screen, emergency team of the operator and intervention of a professional fire brigade) has also reduced the occurrence frequency of emergency scenarios leading to the most serious threats.

The other company Mondi a. s. is a paper producer with headquarters in Ruzomberok. They work with several hazardous substances and therefore it was necessary already at the beginning to carry out a thorough selection for the implementation not to be too extensive. We agreed with the company representatives to work out a model application on the regeneration boiler EK2. We decided for this device because it is an operation where the processes require using several hazardous substances and also due to the fact that MONDI SCP currently builds another regeneration boiler, i.e. a current analysis of this equipment is necessary. In the framework of the overall analysis according to the designed analysis there were several consultations and meetings with specialists and MONDI SCP top management as well as process engineers of this enterprise. The implementation was realised according to the aforementioned procedure and without any complications. For the time being, the last implementation phase is running - we will have to define the consequences and their seriousness. After completing the implementation we will compare the original approach and the new designed one for us to be able to assess the effectiveness and benefits of the methodology designed by the MOPORI project.

Both applications are worked out in independent documents which have several tens of pages and it is impossible to describe them in this article in detail. However, it is possible, even now, to identify a few conclusions which have resulted from the analysis:

- the results of assessment by both approaches differed only minimally, however, they were different in the structure of the required inputs,

- different allocation of correct devices to typological machines in the framework of ARAMIS,

- the left side of the cause tree was not filled/developed due to availability of frequencies of critical events from generic databases,

- the complex model is more structured than the procedure utilised before,

- the complex model is less difficult and less time-demanding,

- the persisting problem of both approaches during final assessments of the effects of occurrence and impacts of major leakages on the inhabitants living in the surroundings.

\section{Conclusion}

At the end it is necessary to assess the results achieved by the project during three years of its solution. First of all it is necessary to point out that the monograph "Prevention of Major Industrial Accidents" will serve not only the enterprises which belong to the SEVESO companies in Slovakia, but especially the students of the Faculty of Security Engineering of the University of Zilina in the subject "Risks of Industrial Processes" which will be taught after its accreditation in 2015 . The signed memoranda about collaboration which are based on real collaboration of the Faculty of Security Engineering of the University of Zilina with companies and creating space for student stays in these institutions will have further value added for the occupational growth of the students. The "Statistical Research of SEVESO Companies" served not only as a basic material in the project framework for processing individual phases and steps of the model, for applications of methods and parts of systematic procedures but also as a basic material for the Department of Environmental Risks and Biological Security at the Slovak Ministry of Environment. E.g. the newly-prepared law about major industrial accidents prevention which will become effective in 2015 will include sending/delivering the safety and security reports in electronic form - the companies declared this in the research unambiguously. A significant step was the creating of the complex model for assessing and managing risks which offers an alternative for the companies to process the problem part of the security and safety documentation [8]. Already today, after the implementation, it is possible to declare that the complex model offers an alternative which is more systematic and from the point of view of time less demanding (if we master the methodology) than the previous model - and this was at the same time the goal of the project. The management of crisis situations is undergoing rapid changes due to advances of Information Technology [9]. The software has also a value added. It contains generic tie-bow diagrams which demonstrate the causes, effects and impacts of a critical event which can lead to a major industrial accident. After removing errors and inaccuracies in the complex model this procedure could be utilised by several companies especially in connection with assessments of security reports and categorisation of companies in 2015.

\section{Acknowledgements}

This work was supported by the Slovak Research and Development Agency under the contract No. APVV-0043-10“ 


\section{References}

[1] Information system of PZPH [online]. [cit. 4.5.2012].Available at: http://www.enviroportal.sk/environmentalne-temy/ starostlivost-o-zp/pzph-prevencia-zavaznych-priemyselnych-havarii/informacny-system-pzph

[2] HOLLA, K., KAMPOVA, K., SIMAK, L., SIMONOVA, M., MIKA, V. Major Industrial Accident Prevention, Zilina : University of Zilina, 2013, 147 p., ISBN 978-80-554-0786-9.

[3] HOLLA, K. et al.: Statistical Survey of SEVESO Establishments in Slovak Republic: project APVV-0043-10 Complex Model for Risk Assessment and Treatment in Industrial Processes, Faculty of Special Engineering: University of Zilina, 22 p., 2013.

[4] SALVI, O. et al: F - SEVESO, 2008. Study of the Effectiveness of the Seveso II Directive, Brussels : EU - Vri, 2008.

[5] The Framework Programme Accidental Risk Assessment Methodology For Industries in the Context of the Seveso II Directive [online]. 2004. [cit. 25.6.2012]. Available at: http://mahb.jrc.it/fileadmin/ARAMIS/downloads/ARAMIS_FINAL_USER_GUIDE.pdf

[6] KITTEL, L., LOVECEK, T.: Passive Protection Elements Breach Resistance Modeling. Communications - Scientific Letters of the University of Zilina, EDIS : University of Zilina, 2011, ISSN 1335-4205.

[7] MOZER, V., HOLLA, K., BUGANOVA, K.: Determination of Ammonia Evaporation Rates for MOPORI Project Model. Advanced Materials Research, vol. 1001, 2014, p. 458-462, ISSN 1022-6680.

[8] ZANICKA HOLlA, K., MORICOVA, V.: Human Factor Position in Rise and Demonstration of Accidents. Communications Scientific Letters of the University of Zilina, vol. 13, No. 2, 2011, pp. 49-52, ISSN 1335-4205.

[9] RISTVEJ, J., ZAGORECKI, A.: Information Systems for Crisis Management - Current Applications and Future Directions, Communications - Scientific Letters of the University of Zilina, vol. 13, No. 2, 2011, pp. 59-63, ISSN 1335-4205. 2011. 